\title{
Rethinking Anatomy: How to Overcome Challenges of Medical Education's Evolution
}

\author{
Repensar a Anatomia: Como Superar os Desafios da \\ Evolução da Educação Médica
}

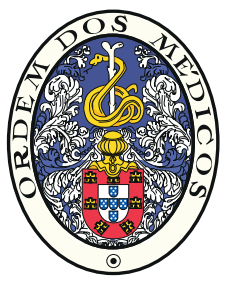

\author{
Bruno GUIMARÃES $\square^{1,2,3,4}$, Luís DOURADO ${ }^{1,2}$, Stanislav $\operatorname{TSISAR}^{1,2}$, José Miguel DINIZ1,2, Maria Dulce MADEIRA ${ }^{1,3}$, \\ Maria Amélia FERREIRA ${ }^{1,2}$ \\ Acta Med Port 2017 Feb;30(2):134-140 - http://dx.doi.org/10.20344/amp.8404
}

\section{ABSTRACT}

Introduction: Due to scientific and technological development, Medical Education has been readjusting its focus and strategies. Medical curriculum has been adopting a vertical integration model, in which basic and clinical sciences coexist during medical instruction. This context favours the introduction of new complementary technology-based pedagogical approaches. Thus, even traditional core sciences of medical curriculum, like Anatomy, are refocusing their teaching/learning paradigm.

Material and Methods: We performed a bibliographic review aiming to reflect on Medical Education's current pedagogical trend, by analysing the advantages of the introduction and diversification of pedagogical approaches in Anatomy Education.

Results: Anatomy Education's status quo is characterized by: less available teaching time, increasing demands from radiology and endoscopy imaging and other invasive and non-invasive medical techniques, increasing number of medical students and other logistical restrains exposed by the current Medical Education scenario. The traditional learning approach, mainly based on cadaveric dissection, is drifting to complementary newer technologies - such as 3D models or 2D/3D digital imaging - to examine the anatomy of the human body. Also, knowledge transfer is taking different channels, as learning management systems, social networks and computer-assisted learning and assessment are assuming relevant roles.

Discussion: The future holds promising approaches for education models. The development of Artificial Intelligence, Virtual Reality and Learning Analytics could provide analytic tools towards a real-time and personalized learning process.

Conclusion: A reflection on Anatomy Education, as a comprehensive model, allows us to understand Medical Education's complexity. Therefore, the present Medical Education context favours a blended learning approach, in which multi-modality pedagogical strategies may become the landmark.

Keywords: Anatomy/education; Education; Medical Education; Medical, Undergraduate

\section{RESUMO}

Introdução: A Educação Médica, face ao desenvolvimento científico e tecnológico, reajustou o enfoque. Progressivamente, o programa curricular em Medicina tem adotado o modelo vertical. Neste modelo, ciências básicas e clínicas coexistem ao longo da formação médica. Este contexto favorece a introdução de novas abordagens pedagógicas de base tecnológica. De facto, áreas de conhecimento tradicionais, como Anatomia, igualmente refocalizaram o seu paradigma de ensino.

Material e Métodos: Nesse sentido, realizamos uma revisão bibliográfica com objetivo de refletir a tendência pedagógica atual da Educação Médica, analisando as vantagens da introdução/diversificação de abordagens pedagógicas em Anatomia.

Resultados: O status quo da Anatomia é caracterizado por menor tempo disponível para o ensino, pela expansão da imagiologia radiológica e endoscópica, bem como, de outras técnicas médicas invasivas/não-invasivas, pelo aumento do número de estudantes e por restrições logísticas inerentes ao presente contexto da Educação Médica. A abordagem pedagógica tradicional, alicerçada na disseção cadavérica, vem sendo complementada por novas tecnologias auxiliares (modelos 3D ou imagiologia digital 2D/3D) ao estudo anatómico. Também, a transmissão de conhecimento vem adotando diferentes vias. Assim, os Sistemas Gestores de Aprendizagem, redes sociais ou plataformas de aprendizagem/avaliação virtuais assumem papéis relevantes.

Discussão: O futuro reserva metodologias educativas promissoras. O desenvolvimento de Inteligência Artificial, da Realidade Virtual e a aplicação dos princípios de Learning Analytics favorece a disponibilização de ferramentas analíticas ao processo de aprendizagem em tempo-real, personalizando-o.

Conclusão: A reflexão sobre a Educação em Anatomia, como modelo compreensivo, permite perceber a complexidade da Educação Médica. Assim, o presente contexto favorece a perspectiva de blended learning, sustentada em estratégias pedagógicas multimodais. Palavras-chave: Anatomia/educação; Blended Learning; Educação Médica; Educação Médica Pré-graduada

\section{INTRODUCTION}

The winds of change of Medical Education began in 1910 with the guide to all medical curricular reforms of the $20^{\text {th }}$ century - the Flexner's Report. ${ }^{1}$ Even though, the need to integrate scientific knowledge with clinical practice (evidence-based medicine) and to train learners' scientific thinking was contemplated, the exponential biomedical

and social sciences evolution was never anticipated, which calls for a much deeper basic, clinical and social sciences' integration. ${ }^{1,2}$

Nowadays, the growth of biomedical knowledge, the technological advancements and social and health policy developments, are, yet again, influencing Medical

1. Department of Biomedicine. Unit of Anatomy. Faculdade de Medicina. Universidade do Porto. Porto. Portugal.

2. Department of Public Health, Forensic Sciences and Medical Education. Unit of Medical Education and Simulation. Faculdade de Medicina. Universidade do Porto. Porto. Portugal.

3. Center for Research in Health Technologies and Information Systems. Faculdade de Medicina. Universidade do Porto. Porto. Portugal.

4. Physical and Rehabilitation Medicine Department. Centro Hospitalar de Entre o Douro e Vouga. Santa Maria da Feira. Portugal.

$\bowtie$ Autor correspondente: Bruno Guimarães. btsguimaraes@med.up.pt.

Recebido: 31 de outubro de 2016 - Aceite: 25 de dezembro de 2016 | Copyright @ Ordem dos Médicos 2017 
Education. ${ }^{3,4}$ That is reflected in medical curriculum's reforms, in which the traditional disciplined-based curricular programme is being replaced by integrative mixed systems and disciplines curricular programme (spiral curriculum). ${ }^{1,5,6}$ These new fields of knowledge can fullfill not only existing gaps in the core curriculum, but also provide non-cognitive skills to learners, essential for clinical practice. ${ }^{2}$ Thus, medical students can immerse themselves in the clinical aspects of the medical curriculum from the beginning of their medical instruction and gradually progress into full clinical practice, without ever losing full contact with basic sciences. As such, through this vertical integration of basic and clinical sciences (Fig. 1), learners can progressively explore the multiple roles of the physician. ${ }^{1,7}$

This status quo change in Medical Education is naturally impacting Anatomy Education, which is facing new pedagogical challenges. As a constant presence in the 'core medical curriculum', Anatomy's relevance is consistent with its role in clinical practice. ${ }^{7}$ Nevertheless, if in the past Anatomy was perceived as being at the heart of medical training, in face of the present Medical Education context, Anatomy has become perceived as a traditionalist and memory-based discipline. ${ }^{7}$

In the framework of the new vertical curricular integration model, which entails the accommodation of new fields of knowledge, the 'core' basic sciences of medical curriculum have been awarded fewer logistical resources and contact time. ${ }^{8}$ In fact, Anatomy has underwent readjustments in its curricular time, since the lecture time assigned to Anatomy Education has been allocated to other innovative and clinically relevant courses (such as medical genetics, immunology or molecular biology)., ${ }^{7,9}$ In just 54 years (1955 - 2009), the time available for teaching Anatomy has decreased from almost 350 hours to 149 hours in numerous faculties. ${ }^{5}$

The presented scenario comprises the traditional Anatomy learning process, which, since its beginning, is mainly based in time-consuming cadaveric dissection. $5,7,10,11$ Nevertheless, favoured by the influence of technology and similar to other fields of Medical Education, Anatomy Education's traditional pedagogical approach has been coping with the introduction and diversification of pedagogical strategies. 3,7
The present review article sought to reflect on the possible advantages of Medical Education new pedagogical approaches. In order to achieve this objective, we propose the analysis of Anatomy Education state of the art, namely by examining the possible advantages relative to the implementation/diversification of pedagogical approaches/ strategies in this field.

\section{MATERIAL AND METHODS}

We performed a comprehensive review of the literature from indexed articles in Medline (through PubMed), ISI Web of Science, Scopus databases and Google Scholar search engine, from January 1991 until October 2016, written in English, Portuguese, Italian or Spanish.

The keywords used for this search were related to the field of Anatomy Education, including 'Medical Education' (MeSH Term), 'continuing Medical Education' (MeSH Term), 'medical curriculum', 'Anatomy Education', 'Anatomy Education history', 'anatomy curricular reform', 'simulation methodologies teaching medical schools' and 'Learning Analytics'.

A framework for published medical research's critical appraisal and a checklist for sources of bias were used in the study's quality assessment. We included a total of 33 literature reviews and 30 original articles. Considering the word restriction, all the included literature was considered to be the most relevant to answer the question raised.

\section{RESULTS}

\section{The current Anatomy Education scenario}

The current Anatomy Education scenario is characterized by logistical and financial restrains. ${ }^{3,8}$

Indeed, as previously stated, not only the teaching time has been reduced (e.g. in Faculty of Medicine, University of Porto (FMUP), the hours dedicated to anatomy courses decreased from 309 hours to 180.5 hours after the curricular reform of 2013), but also there is usually a lack of rational adaptation of the Anatomy program to the new curriculum, in order to contextualize the gross anatomy teaching with the clinical practice. ${ }^{8,12}$ In this context, the introduction of laparoscopic and endoscopic procedures in various fields of diagnostic medicine and surgery parallel with the

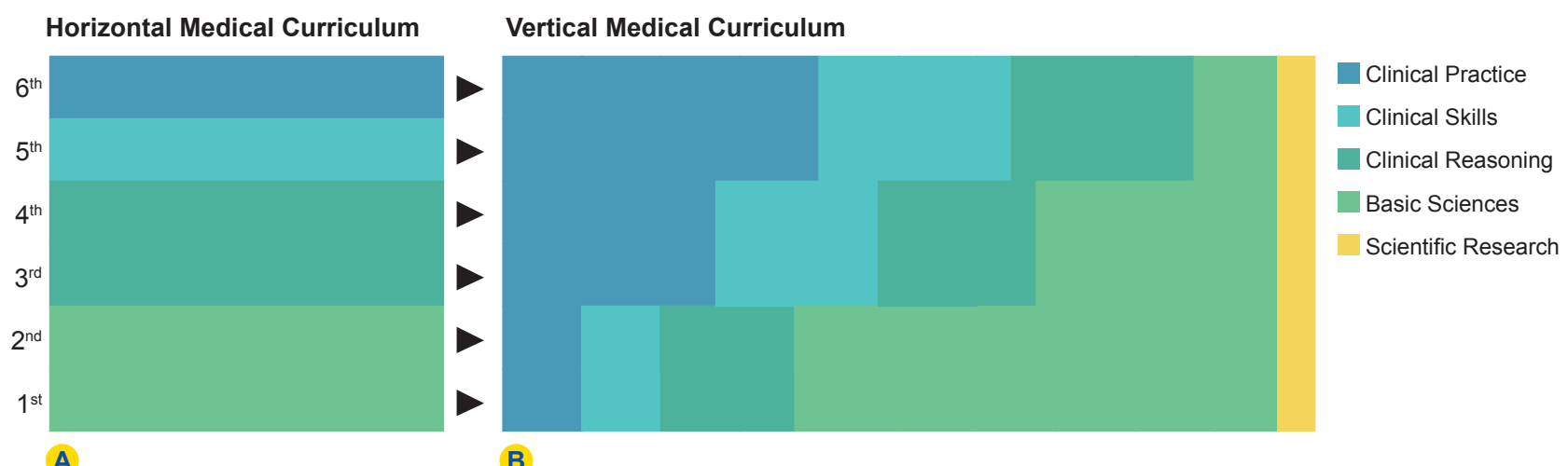

Figure 1 - The shift in medical curriculum from traditional $(A)$ to vertical integration model $(B)$ 
evolution of medical imaging techniques, such as magnetic resonance imaging (MRI) or computed tomography (CT), providing new approaches to human body visualization. ${ }^{13-15}$ Therefore, considering the augmented importance that medical imaging and endoscopic techniques have in clinical practice, the clinically oriented knowledge of topographic and cross-sectional anatomy approach is perhaps more relevant than the classical gross anatomy approach. ${ }^{8}$

On the other hand, Anatomy departments are increasingly facing contractual restrains of teaching staff, because of the revaluation of funds distribution between departments. ${ }^{16}$ As a consequence, there may be a lack of experienced professionals to teach Anatomy, as the decrease of medical/ non-medical teaching staff ratio become evident, along with the shift of Anatomy departments agenda from teaching to research activities. ${ }^{12,17}$

Additionally, logistical and financial constraints imply new burdens regarding the sustainability of the dissecting room/ Anatomy theatre and of the cadaveric material (cadavers need to be correctly transported, dissected, stored and finally precautions need to be taken for their respectful disposal). ${ }^{12}$ The availability of cadaveric material is a limiting factor in dissection/prosection teaching. The lack of cadaveric donations and the friability of cadaveric material with its constant usage encourage some departments to abandon its handling. ${ }^{18,19}$ Also, there are difficulties in eliminating the risks associated with cadaver contacts (e.g. prion disease and toxicity of fixative products) and the psychological impact on learners may be problematic., ${ }^{9,20}$

Even though anatomical dissection, the traditional teaching approach, is regarded by many as the best and convenient teaching method, ${ }^{21}$ there is no possible way to guarantee its benefits within the current framework.

Finally, in some cases, like in Portugal, the excess number of students that enrol in medical schools may compromise Anatomy teaching and Medical Education in general. ${ }^{22}$

\section{The consequences of Anatomy curriculum reform}

Despite the changes in recent decades, Anatomy Education has still a paramount importance in medicine..$^{3,7}$ Some important medical tasks, as physical examination, interpretation of radiological imaging or execution of invasive procedures, transversal to medical specialities, demand basic/advanced knowledge in Anatomy. ${ }^{7}$

Nevertheless, among undergraduates, postgraduates and clinicians, there are concerns regarding their own Anatomy knowledge towards medical practice standards. ${ }^{23}$ The lack of anatomical knowledge may compromise the diagnostic capacity of the physicians and have a hazardous effect in surgical practice. In fact, there was a 7-fold increase in claims concerning anatomical errors, in just five years (1995 - 2000), as $32 \%$ of these errors were, in general and vascular surgery, classified as "damage to underlining structures". ${ }^{24}$

Moreover, insufficient knowledge in Anatomy compromises the correct and efficient identification of anatomical structures in medical imaging or even by physical examination by junior doctors. ${ }^{25}$

\section{From plan to action: how to overcome the challenges posed by the shift in the medical curriculum}

Noteworthy, the influence of technology has never had as much impact before, favouring new approaches and the modernization of medical curricula. Therefore, the use of technology-based methodologies in Anatomy Education, as a complementary approach for learning and assessment processes, is becoming a common solution for stated challenges (Fig. 2).

3D Models of the human body are a viable supplement for human body visualization. Highly durable and with minimal costs, these models are a useful introduction to the Anatomy course for its ability to simplify the approach to complex anatomical structures and supply learners with only the most relevant information. Moreover, it is well suited for teaching spatial relations of structures, regardless of its low fidelity. ${ }^{9,26,27}$

Printing 3D copies of cadavers or of regional sections can now be produced, solving the fidelity issue. These 3D printed models are an inexpensive, durable and accurate solution for the lack of cadavers. ${ }^{28}$ Another alternative is 3D visualization technologies (3DVT). Computer models in $3 D$ provide learners with unlimited time for exploration of the material, providing an expansive spatial perception of structures and their relations from a wide range of perspectives. $^{29}$

Furthermore, social media networks can be an important way to promote the learning of Anatomy. Because it's comprised by platforms for user-generated content, it allows the exchange of ideas and content between users, enhancing self-reflection. ${ }^{30}$ Additionally, there are multiple image and video data banks from which Anatomy can be studied. In fact, Jaffar described the usage of YouTube ${ }^{\circledR `} \mathrm{~s}$ Human Anatomy Education Channel, that contains over four hours of video highlighting practical aspects of Anatomy by cadaver dissections, 3D models and surgical operations; as a teaching auxiliary that guaranteed students' positive satisfaction rate. ${ }^{31}$

The introduction of e-learning platforms, mainly learning management systems (LMS), like Moodle ${ }^{\circledR}$ or Blackboard ${ }^{\circledR}$, created new formats for learners' interactions with Anatomy knowledge content. ${ }^{18,32}$

Accordingly, there are descriptions of fully computerassisted learning $(\mathrm{CAL})$ online undergraduate Anatomy courses with different combinations of interactive laboratory component implementations, designed to provide both the content (slide shows, lecture broadcast (audio and video) and 3D anatomical models) and the needed support (live questions during lectures and face-to-face help from teachers). ${ }^{33-35}$

With such a big scope of applications, CAL can be used as a learning tool - as a means to distribute the content, e.g. lectures, interactive 3D models, live questions - and as an evaluation manager, e.g. quizzes and identification of 


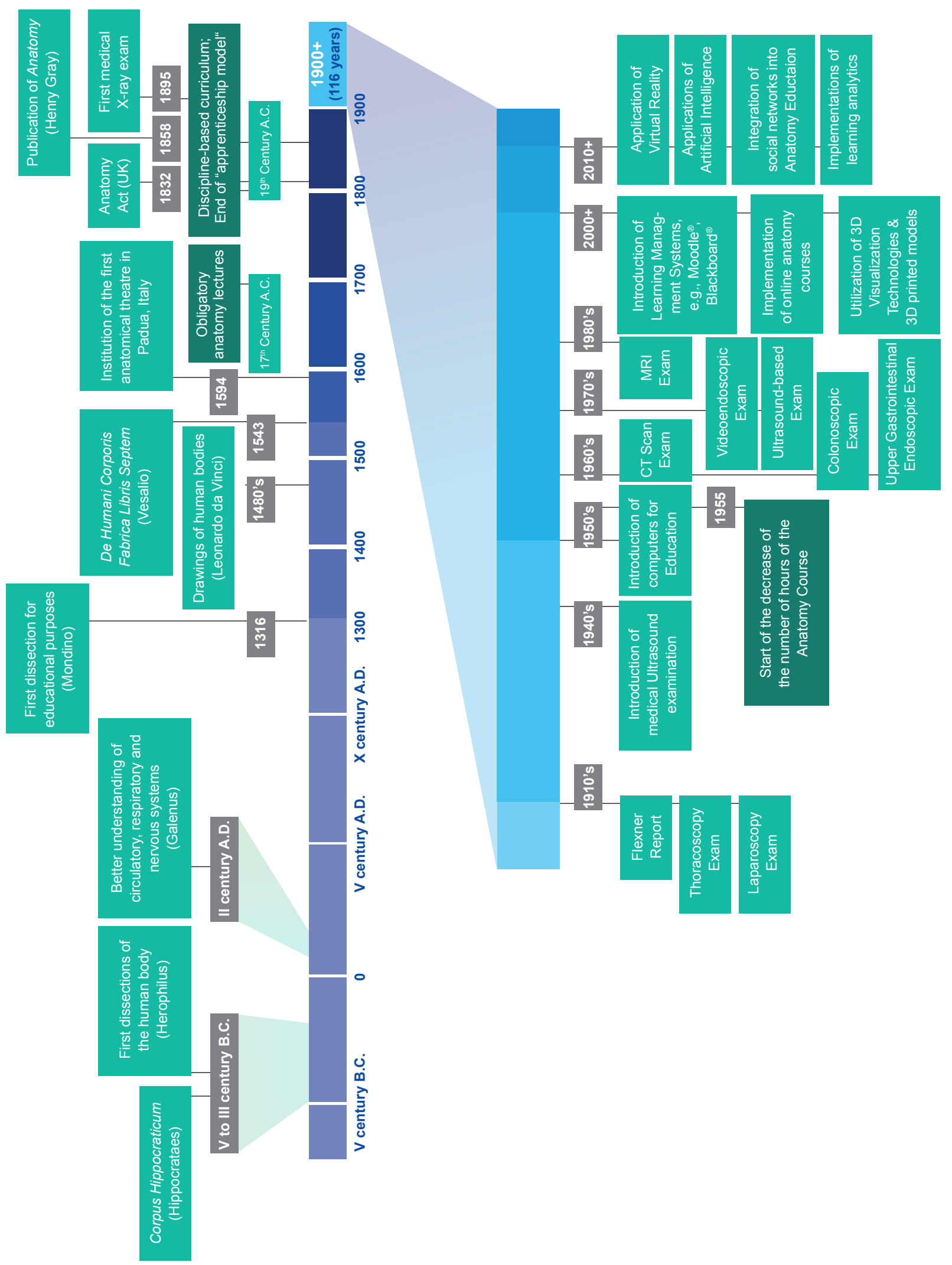


anatomical structures. ${ }^{33-35}$

As seen, computerized environments have been applied in the assessment process in Anatomy Education. ${ }^{18,36,37}$ Generally, Anatomy courses evaluate learners' identification of anatomical structures skills through the practical examination, the steeplechase, ${ }^{18}$ which consists in a sequence of stations, displaying prosections, dissections and/or radiological images with pins pointing specific structures, and learners' anatomical core knowledge (anatomical basic knowledge, anatomical correlations, clinical applied anatomical knowledge) through theoretical examination. ${ }^{38}$ The adaptation of these assessment formats to computer-based assessment (CBA) allows the simulation of traditional anatomy assessment modalities, such as steeplechase ${ }^{18,36,37}$ and clinical vignettes. ${ }^{39,40}$

CBA allows better assessment of learners' performance, as well as, the metrics associated to the examination. ${ }^{39,40}$

\section{The future of Anatomy Education: a new reality, better feedback and personalised approaches}

As previously stated, human body visualization is drifting away from the traditional cadaveric model, in order to accommodate a technological approach. In this context, virtual reality systems, by creating a more immersive experience than $2 \mathrm{D}$ and $3 \mathrm{D}$ visualization technologies, are seen as auxiliary tools for human Anatomy learning, especially due to visually and spatially complex concepts. ${ }^{41,42}$

The application of Learning Analytics (LA) principles in Anatomy Education might represent the next step in a truly student-centered learning approach. LA is the measurement, collection, analysis, and reporting of data about learners and their contexts, for the purpose of understanding and optimizing learning and the environments in which it occurs. ${ }^{43,44}$ As a matter of fact, the learners' data regarding their interaction with LMS, CAL or CBA platforms, during learning/assessment processes, once analysed, might be essential to integrate new pedagogical strategies for the purpose of understanding and optimizing learning. ${ }^{43,44}$

From the teacher's perspective, the outcomes from this systemic data analysis allows a better perception of learners' knowledge (supporting implementation of alterations in teaching process according to the learners' difficulties) and the curation of question-banks with the intent of improving the assessment process. ${ }^{45}$

From the learner's perspective, the application of LA systems allows for a personalized guidance, namely by providing an individual feedback, in line with the performance and knowledge. This information might lead to a personalization of the learning process, stimulating learners to manage their own learning process and to undertake a targeted study approach. ${ }^{45}$

Lastly, the implementation of artificial intelligence (AI) in LA-oriented systems can identify learners' understanding and predict their behaviour. ${ }^{46}$ Recent progresses already provide the means to 'real-time' feedback-response recalibration of content, with the system automatically providing learning activity and learning adaption recommendations to improve learners' learning motivation and learning success. ${ }^{47}$

\section{DISCUSSION}

Since its inception, Anatomy Education has relied on cadaveric material as a subject of study and on traditionalistic dissection/prosection as a teaching model. Despite this approach being firmly established in the current Medical Education paradigm, its implementation is deemed unpractical. ${ }^{21}$

In sequence of less teaching hours, a greater number of students enrolling in medical schools and logistical retrains as well as the increasing influence of technology in medical practice, Anatomy Education is facing a teaching/ learning paradigm shift, ${ }^{3,5}$ favouring a multi-modal pedagogical approach through blended learning. ${ }^{48}$ With this approach, the traditional face-to-face learning congregates with new heavily technological-based pedagogical strategies. ${ }^{49,50}$

Despite some concerns surrounding the implementation and maintenance costs as well as its potential to depersonalize the learning environment or to lead to the isolation of students, ${ }^{49}$ blended learning approaches applied in Anatomy Education have demonstrated effectiveness ${ }^{51}$ and collected positive perceptions from students and teachers. ${ }^{52}$ That evidence is in line with reports from the implementation of blended learning in Medical Education. ${ }^{49,53}$

As such, the application of blended learning approaches in Anatomy Education can provide a more accessible way to study and visualize the human body (3DVT, 3D printing, 3D models and VR). ${ }^{9}$ In fact, Lim et al, by comparing the use of cadaveric materials with $3 \mathrm{D}$ printed models, concluded that the usage of the former lead to better results on assessments. ${ }^{54}$ Keedy et al, by comparing the usage of 3D computer models with the traditional method for teaching the hepatobiliary system, observed a greater satisfaction and ease of use with 3D computer models, which could translate in a better engagement and improved results. ${ }^{55}$ Similarly, Yammine and Violato showed that the pedagogical use of 3DTV yields better results when compared to their 2D counterparts, regarding learning factual Anatomy, with substantial educational benefits on spatial Anatomy knowledge. ${ }^{56}$

Also, this learning perspective might contribute to improving the connection and feedback between teacher and students, for instance through social media network ${ }^{30,31}$ and, subsequently, cause an impact in learner's performance. ${ }^{57}$

The introduction of computer integrated systems in Anatomy Education lends itself to a better analysis of the teaching-learning-assessment dimensions, at the same time, delivering new environments to that processes. Moreover, it became possible to analyse the learning process and provide multimedia resources and out-ofschool access to educational content (CAL platforms), ${ }^{33-35}$ to assess Anatomy content and collect/analyse inherent data of students' performance (CBA platforms) ) $^{58}$ and to manage and distribute this content (LMS). ${ }^{32}$ In fact, coupling LA systems with CAL and CBA platforms, allows the overview of: learners' learning activity, the usage of the available 
pedagogic resources and the quality of the examinations performed (by evaluating the metric data associated with the examination and with each question - difficult index, discrimination index, Cronbach's alpha, among others measures) and, consequently, correlating this information with learners' performance.44,59 On the other hand, CBA can offer several advantages over the traditional pen-andpaper format. Actually, its application can attenuate the staff workload by simplifying the designing, application and correction of the examinations, ${ }^{37}$ by increasing examination security $^{37}$ and by providing immediate performance feedback to the student and the teacher. ${ }^{60}$ It also allows a more promptly collection and analysis of information on learner's performance, ${ }^{61}$ facilitating item banking and the collection of item statistics ${ }^{18}$ as well as helping to attenuate the wear and tear of cadaveric material. ${ }^{18}$

Blended learning is consistent with a more self-directed, student-centered approach and is supported by the current technological framework of society.49,50,53 That portrays the more recent pedagogical strategies implemented in Anatomy Education, which focus on a more personalized guidance. Indeed, the application of LA principles values the individual analysis and feedback of each singular student.44,45 Also, Al supporting systems, by analysing patterns and learners metric data, can contribute to individual study effectiveness. ${ }^{46}$

The continuous development of supporting pedagogical strategies, which reflect Medical Education's increasingly complexity and mutability, is expected. ${ }^{49,53}$

\section{REFERENCES}

1. Irby DM, Cooke M, O'Brien BC. Calls for reform of medical education by the Carnegie Foundation for the Advancement of Teaching: 1910 and 2010. Acad Med. 2010;85:220-7.

2. Martins e Silva J. Educação médica e profissionalismo. Acta Med Port. 2013;26:420-7.

3. Drake RL, McBride JM, Lachman N, Pawlina W. Medical education in the anatomical sciences: The winds of change continue to blow. Anat Sci Educ. 2009;2:253-9.

4. Romãozinho JM. The reform of medical education. Some reflections. Acta Med Port. 1995;8:187-90.

5. Drake RL. A retrospective and prospective look at medical education in the United States: Trends shaping anatomical sciences education. J Nat. 2014;224:256-60.

6. Coelho C, Moles D. Student perceptions of a spiral curriculum. Eur J Dent Educ. 2015;20:161-6.

7. Turney B. Anatomy in a modern medical curriculum. Ann R Coll Surg Engl. 2007;89:104-7.

8. Leung KK, Lu KS, Huang TS, Hsieh BS. Anatomy instruction in medical schools: connecting the past and the future. Adv Health Sci Educ Theory Pract. 2006;11:209-15.

9. Sugand K, Abrahams P, Khurana A. The anatomy of anatomy: a review for its modernization. Anat Sci Educ. 2010;3:83-93.

10. McLachlan JC, Patten D. Anatomy teaching: ghosts of the past, present and future. Med Educ. 2006;40:243-53.

11. Hadzic A, Sadeghi N, Vandepitte C, Van de Velde M, Hadzic A, Van Robays J, et al. 500th birthday of Andreas Vesalius, the founder of modern anatomy: "vivitur ingenio, caetera mortis erunt" ("genius lives on, all else is mortal”). Reg Anesth Pain Med. 2014;39:450-5.

12. Bergman EM, Verheijen IW, Scherpbier AJ, Van der Vleuten CP, Bruin AB. Influences on anatomical knowledge: The complete arguments. Clin Anat. 2014;27:296-303.

13. Liebscher L, Sherry C, Breslau J, Dodd G, Fleishon H, Larson P, et al. The general radiologist in the 21st century. J Am Coll Radiol. 2012;9:5549.
Nevertheless, the consolidation and assimilation of the blended learning in Anatomy and Medical Education will depend on the continuous evaluation of the implemented methodologies. ${ }^{62,63}$

\section{CONCLUSION}

Anatomy education, a core science of medical curriculum, can behave as a model capable of portraying Medical Education and its on-going changes in a time of increasing scientific knowledge and social awareness.

Under the current paradigm and in face of different restrains, Anatomy Education has been and must promote the introduction of student-centered and technology-based methodologies as a means to diversify teaching towards a blended learning approach.

Hence, it is our belief that the trend in Anatomy Education towards the standardization of a multi-modal approach based on technology will spread to numerous fields of Medical Education, building a new pedagogical practice reflective of its intricacies.

\section{CONFLICTS OF INTEREST}

The authors declare that there are no conflicts of interest.

\section{FUNDING SOURCES}

This research received no specific grant from any funding agency in the public, commercial, or not-for-profit sectors.

14. Spaner SJ, Warnock GL. A brief history of endoscopy, laparoscopy, and laparoscopic surgery. J Laparoendosc Adv Surg Tech. 1997;7:369-73.

15. Doi K. Diagnostic imaging over the last 50 years: research and development in medical imaging science and technology. Phys Med Biol. 2006;51:R5

16. Kerby J, Shukur ZN, Shalhoub J. The relationships between learning outcomes and methods of teaching anatomy as perceived by medical students. Clin Anat. 2011;24:489-97.

17. Vazquez R, Riesco JM, Carretero J. Reflections and challenges in the teaching of human anatomy at the beginning of the 21 st century. Eur $\mathrm{J}$ Anat. 2005;9:111

18. Inuwa IM, Taranikanti V, Al-Rawahy M, Habbal O. Anatomy practical examinations: How does student performance on computerized evaluation compare with the traditional format? Anat Sci Educ. 2012;5:27-32.

19. Gunderman RB. Giving ourselves: The ethics of anatomical donation. Anat Sci Educ. 2008;1:217-9.

20. McLachlan JC, Bligh J, Bradley P, Searle J. Teaching anatomy without cadavers. Med Educ. 2004;38:418-24.

21. Böckers A, Jerg-Bretzke L, Lamp C, Brinkmann A, Traue HC, Böckers TM. The gross anatomy course: an analysis of its importance. Anat Sci Educ. 2010;3:3-11.

22. Diogo PG, Moreira A, Coimbra A, Silva AC, Martins AN, Mendonça C, et al. Estudo sobre as condições pedagógicas das escolas médicas portuguesas: uma análise nacional sobre a satisfação estudantil, rácios estudante-tutor e número de admissões. Acta Med Port. 2016;29:301-9.

23. Bergman E, Van Der Vleuten CP, Scherpbier AJ. Why don't they know enough about anatomy? A narrative review. Med Teach. 2011;33:403-9.

24. Ellis H. Medico-legal litigation and its links with surgical anatomy. Surgery. 2002;20:i-ii.

25. Roche A, Williams G, Wharton D, Brown D. Physical and radiographic identification of the bones of the wrist by junior doctors. J Hand Surg Eur Vol. 2011;36:107-10.

26. Chan LK, Cheng MM. An analysis of the educational value of low- 
fidelity anatomy models as external representations. Anat Sci Educ. 2011;4:256-63.

27. Johnson EO, Charchanti AV, Troupis TG. Modernization of an anatomy class: From conceptualization to implementation. A case for integrated multimodal-multidisciplinary teaching. Anat Sci Educ. 2012;5:354-66.

28. McMenamin PG, Quayle MR, McHenry CR, Adams JW. The production of anatomical teaching resources using three-dimensional (3D) printing technology. Anat Sci Educ. 2014;7:479-86.

29. Attardi SM, Choi S, Barnett J, Rogers KA. Mixed methods studen evaluation of an online systemic human anatomy course with laboratory. Anat Sci Educ. 2015;9:272-85.

30. McKenna MP, D'Alessandro D. Social networks and the practice of medicine: harnessing powerful opportunities. J Pediatr. 2011;158:1-2.

31. Jaffar AA. YouTube: an emerging tool in anatomy education. Anat Sci Educ. 2012;5:158-64.

32. Bucarey AS, Araya AE, Cabezas OX, Alvarez GL. Anatomy contents in learning designs displayed in LAMS and integrated to Moodle. Int $\mathrm{J}$ Morphol. 2011;29:363-70.

33. Attardi SM, Rogers KA. Design and implementation of an online systemic human anatomy course with laboratory. Anat Sci Educ. 2015;8:53-62.

34. Attardi SM, Barnett J, Rogers K. Mixed methods evaluation of an online undergraduate systemic human anatomy course with laboratory (211.1). FASEB J. 2014;28:S211.1.

35. Mathiowetz V, Yu CH, Quake-Rapp C. Comparison of a gross anatomy laboratory to online anatomy software for teaching anatomy. Anat Sci Educ. 2016;9:52-9.

36. Meyer AJ, Innes SI, Stomski NJ, Armson AJ. Student performance on practical gross anatomy examinations is not affected by assessment modality. Anat Sci Educ. 2016;9:111-20.

37. Daly FJ. Use of electronic anatomy practical examinations for remediating "at risk" students. Anat Sci Educ. 2010;3:46-9.

38. Severo M, Tavares MA. Meta-evaluation in clinical anatomy: A practical application of item response theory in multiple choice examinations. Anat Sci Educ. 2010;3:17-24.

39. Guimarães B, Arantes M, Severo M, Ferreira MA. Development of a web-based application as a tool towards continuous education in neuroanatomy. INTED2015 Proceedings. 2015:99-103.

40. Guimarães B, Gomes N, Mota J, Carmo J, Severo M, Ferreira M. Design of a web-based application towards improving acquisition of cognitive skills clinical anatomy. EDULEARN13 Proceedings. 2013:5938-40.

41. de Faria JWV, Teixeira MJ, de Moura Sousa Júnior L, Otoch JP, Figueiredo EG. Virtual and stereoscopic anatomy: when virtual reality meets medical education. J Neurosurg. 2016;125:1105-11.

42. Kockro RA, Amaxopoulou C, Killeen T, Wagner W, Reisch R, Schwandt $\mathrm{E}$, et al. Stereoscopic neuroanatomy lectures using a three-dimensional virtual reality environment. Ann Anat. 2015;201:91-8.

43. Gasevic DM, Long P, Dawson D. Editorial - Inaugural Issue of the Journal of Learning Analytics. J Learning Analyts.1:1-2.

44. Siemens G. Learning analytics: the emergence of a discipline. Am Behav Sci. 2013;57:1380-400.

45. Ferguson R. Learning analytics: drivers, developments and challenges. Int J of Technol Enhanced Learning. 2012;4:304.

46. Jain GP, Gurupur VP, Schroeder JL, Faulkenberry ED. Artificial intelligence-based student learning evaluation: A concept map-based approach for analyzing a student's understanding of a topic. IEEE Trans Learn Technol. 2014;7:267-79.

47. Pedrazzoli A. OPUS one: an intelligent adaptive learning environment using artificial intelligence support. Paper presented at: IAENG Transactions On Engineering Technologies: Volume 4: Special Edition of the World Congress on Engineering and Computer Science 2009/2010.

48. Heptonstall N, Ali T, Mankad K. Integrating radiology and anatomy teaching in medical education in the UK - the evidence, current trends, and future scope. Acad Radiol. 2016;23:521-6.

49. Liu Q, Peng W, Zhang F, Hu R, Li Y, Yan W. The effectiveness of blended learning in health professions: systematic review and meta-analysis. J Med Internet Res. 2016;18:e2.

50. Morton CE, Saleh SN, Smith SF, Hemani A, Ameen A, Bennie TD et al. Blended learning: how can we optimise undergraduate student engagement? BMC Med Educ. 2016;16:195.

51. Pereira JA, Pleguezuelos E, Meri A, Molina-Ros A, Molina-Tomás MC, Masdeu C. Effectiveness of using blended learning strategies for teaching and learning human anatomy. Med Educ. 2007;41:189-95.

52. Ocak MA, Topal AD. Blended learning in anatomy education: a study investigating medical students' perceptions. Eurasia J Math Sci Tech Ed. 2015;11:647-83.

53. Milic NM, Trajkovic GZ, Bukumiric ZM, Cirkovic A, Nikolic IM, Milin JS, et al. Improving education in medical statistics: implementing a blended learning model in the existing curriculum. PLoS One. 2016;11:e0148882.

54. Lim KHA, Loo ZY, Goldie SJ, Adams JW, McMenamin PG. Use of 3D printed models in medical education: A randomized control trial comparing $3 \mathrm{D}$ prints versus cadaveric materials for learning external cardiac anatomy. Anat Sci Educ. 2015;9:213-21.

55. Keedy AW, Durack JC, Sandhu P, Chen EM, O'Sullivan PS, Breiman RS. Comparison of traditional methods with $3 D$ computer models in the instruction of hepatobiliary anatomy. Anat Sci Educ. 2011;4:84-91.

56. Yammine K, Violato C. A meta-analysis of the educational effectiveness of three-dimensional visualization technologies in teaching anatomy. Anat Sci Educ. 2015;8:525-38.

57. Saxena V, Natarajan P, O'Sullivan PS, Jain S. Effect of the use of instructional anatomy videos on student performance. Anat Sci Educ. 2008;1:159-65.

58. Jin J, Bridges SM. Educational technologies in problem-based learning in health sciences education: a systematic review. J Med Internet Res. 2014;16:e251.

59. Pecaric M, Boutis K, Beckstead J, Pusic M. A big data and learning analytics approach to process-level feedback in cognitive simulations. Acad Med. 2016;92:175-84.

60. Krippendorf BB, Bolender DL, Kolesari GL. Computerized grading of anatomy laboratory practical examinations. Anat Sci Educ. 2008;1:2203.

61. Torke S, Upadhya S, Abraham RR, Ramnarayan K. Computer-assisted objective-structured practical examination: an innovative method of evaluation. Adv Physiol Educ. 2006;30:48-9.

62. Ellaway R. E-learning: is the revolution over? Med Teach. 2011;33:297302.

63. Sandars J, Morrison C. What is the net generation? The challenge for future medical education. Med Teach. 2007;29:85-8. 